\title{
The capability approach: a guiding framework to improve population health and the attainment of the Sustainable Developmental Goals
}

\author{
Shela Akbar Ali Hirani ${ }^{7}$ and Solina Richter ${ }^{1}$
}

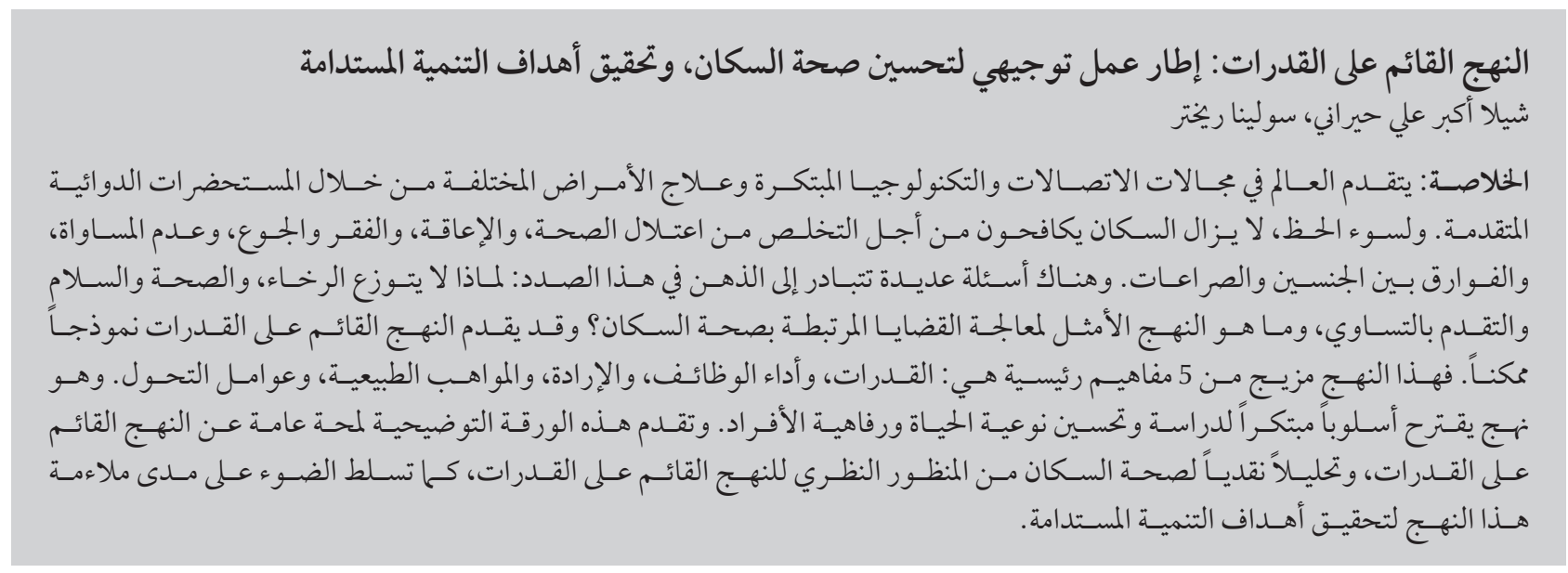

ABSTRACT The world is progressing in terms of communication, innovative technology and cure of various diseases through advanced pharmacological preparations. Unfortunately, populations are still struggling with ill-health, disabilities, poverty, hunger, inequality, gender disparities and conflicts. Several questions come to mind in this regard: why are prosperity, health, peace and progress not evenly distributed and what is the best approach to address the issues associated with population health? The capability approach may offer a possible model. This approach is a blend of 5 key concepts: capabilities, functioning, agency, endowment, and conversion factors. It proposes an innovative approach to examine and enhance the quality of life and wellbeing of individuals. This reflective paper provides an overview of the capability approach, critically analyses population health from the theoretical lens of the capability approach and highlights the relevance of this approach to achieving the Sustainable Developmental Goals.

L'approche par les capacités : cadre d'orientation pour l'amélioration de la santé des populations et la réalisation des objectifs de développement durable

RÉSUMÉ Le monde évolue dans les domaines de la communication, des technologies innovantes et de la guérison de différentes maladies grâce à des traitements pharmaceutiques avancés. Malheureusement, les populations continuent de lutter contre la mauvaise santé, le handicap, la pauvreté, la faim, les inégalités, les disparités entre les sexes et les conflits. Plusieurs questions se posent à cet égard : pour quelles raisons la prospérité, la santé, la paix et le progrès ne sont-ils pas répartis de façon égale et quelle est la meilleure approche pour régler les problèmes liés à la santé des populations ? L'approche par les capacités pourrait servir de modèle potentiel. Elle repose sur cinq concepts clés, à savoir : les capacités, les fonctionnements, l'agentivité, les ressources, et les facteurs de conversion. Elle propose une méthode innovante pour analyser et améliorer la qualité de vie et le bien-être des individus. Le présent document de réflexion offre un aperçu de l'approche par les capacités, procède à une analyse critique de la santé des populations à travers le prisme théorique de l'approche par les capacités et souligne la pertinence de cette approche dans la réalisation des objectifs de développement durable. 


\section{Introduction}

In this century, our world is progressing in terms of narrowing the communication gap through the use of information technology, saving time and effort through the invention of innovative machines, and curing various diseases through advanced pharmacological preparations. Unfortunately, populations around the globe are still struggling with issues like ill-health, disability, poverty, hunger, inequality, gender disparities and conflicts. Reflecting on these issues of our modern world, several questions come to mind: why are prosperity, health, peace and progress not evenly distributed and what would be the best approach to address the issues associated with population health? To answer these questions, this reflective paper provides an overview of the capability approach, critically analyses population health from the theoretical lens of the capability approach and highlights the relevance of this approach to achieve the Sustainable Developmental Goals.

\section{Capability approach: an overview}

The notion of human capability was first introduced by Nobel prize winner Amartya Sen in 1979 (1,2). Later, the concepts surrounding human capability were developed to the level of an analytical and normative theoretical framework (2). As this framework was developed while considering interdisciplinary perspectives, it is relevant to a wide range of disciplines, such as human development, nursing, medicine, public health, health economics, sociology, psychology, social policy and political philosophy (3-6).

This framework is a blend of 5 key concepts: capabilities, function, agency, endowment and conversion factors (2). The concept of capability is reflective of possible and available opportunities that an individual possesses, while function reflects the choice, values and willingness of an individual to pursue those opportunities. Agency refers to an individual's ability to act and demonstrate freedom to achieve set goals. Endowment refers to resources (monetary, physical, mental, social, public or political) available to individuals that can further reinforce their capabilities. The concept of conversion factors refers to the contextual characteristics (personal, social or environmental) that positively or negatively affect an individual's capabilities and functioning (2).

This framework proposes an innovative approach to examining and enhancing the quality of life and wellbeing of individuals by considering the opportunities available to them, their personal values, their ability to avail those opportunities, the availability of resources and the contextual characteristics to achieve desirable outcomes in their lives $(4,7)$. It can be considered that all 5 concepts in this framework are interrelated and sufficient to reinforce the power of each other.

According to the framework, an individual's internal environment (knowledge, skills, biology and genetic predisposition) and external environment (social, political and geographic) affect human capabilities and functioning (4). Although the capability approach adapts the notion of environmental influences on human beings from the ecological framework, the uniqueness of this framework is consideration of the influence of human values, freedom, resources and contextual diversity in enhancing or minimizing human capabilities and functioning. Figure 1 highlights the factors affecting human capabilities and functioning and depicts the interrelationship between these factors.

Capabilities create functioning which creates more capabilities which can be influenced positively and negatively by the factors identified in Figure 1. It is important to note that all these factors are interrelated. It is not possible to focus on one single factor: for example knowledge and skill, which are listed as individual factors (internal environment), are strongly related to factors in the external environment, such as social, political and geographical location. Human capabilities and functions are additionally influenced by human

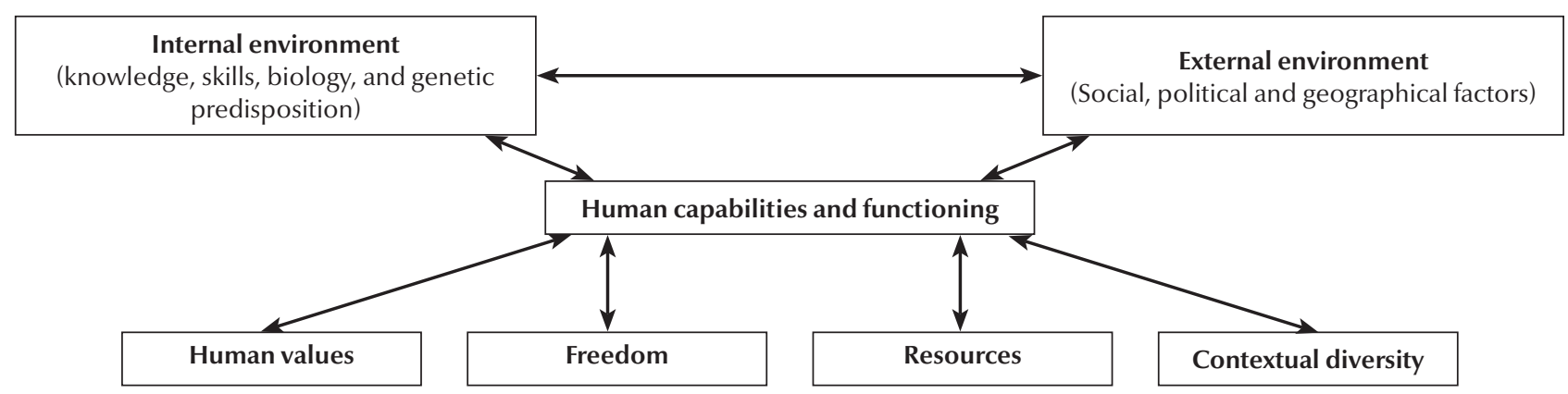

Figure 1 Factors affecting human capabilities and functioning 
values, freedoms, resources allocations and contextual diversity.

\section{Population health from the lens of the capability approach}

Promoting population health has always been the target of health care agencies, policy-makers, health care professionals and researchers; however, achievement of this target has always remained a challenge. Analysis of the literature reveals that although the capability approach is not a health care framework, it can effectively address the notions surrounding population health, including the human right to health, quality of life, health policy and health economics (5,7-9).

In our world, where issues like poverty and inequality are still prevalent, it seems essential to have a thorough assessment of the measures of poverty and inequality in order to be able to design a well-thought-out programme that can empower a vulnerable population. Stakeholders often consider assessing poverty, inequality and well-being through measures like income, household size, utilities and liabilities (4). Negating this practice, the capability approach suggests considering human capabilities to assess, analyse and resolve issues like poverty, inequality and affected well-being $(4,6)$. Using the theoretical lens of the capability approach can be useful in diagnosing population health issues and designing contextspecific needs-based programmes for a targeted population with specific sets of capabilities, functioning, agency, resources and contextual factors. Figure 2 depicts the suggested approach to design and execute programmes, policies and practices to improve population health. This approach can be a guide to programmes, policies and practice development. Using the capabilities approach it is clear that factors related to agency, resources and context need to be considered in the development and planning phases in order to increase the likelihood of success in increasing the capabilities and function of the target population and ultimately achieving the population health goals. A programme, policy and practice cannot apply universally to all populations; it needs to be adapted by considering the factors which influence human capabilities (depicted in Figure 1).

A thorough understanding of this framework can empower stakeholders to critically analyse why some programmes end in failure and some do not. It can be reflected that an analysis of the capabilities and functioning of the targeted population is useful to save resources, efforts and time, as well as to foster the capabilities, functioning, compliance and well-being of the targeted population. For instance, in a target population where the maternal mortality rate is high due to inadequate birth spacing, it can be argued that interventions such as the provision of free access to permanent methods of family planning at reproductive health centres may likely fail. From the perspective of the capabilities framework, this project may end in failure if the targeted population is reluctant to utilize the permanent method of family planning because their personal values are in conflict with the health care advice (affected capability and functioning). Further, women can often not act against social norms

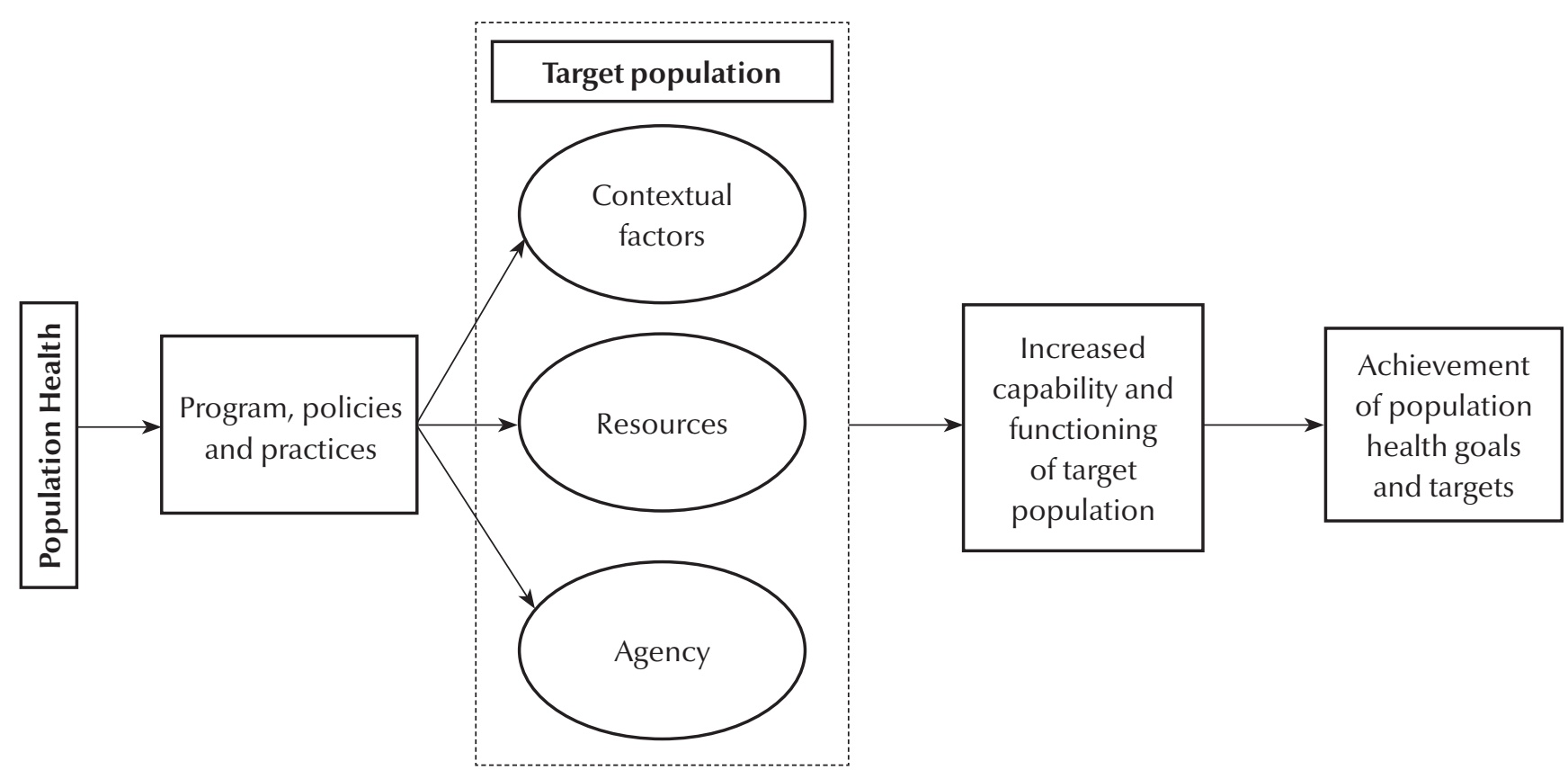

Figure 2 Using capability approach to design and execute population health proagramme, policies and practices 
and their partner's will to have many children (agency). They have available and adequate resources to bear large families and have the child care measures that are supported by the country's government (endowment), and/or their culture or religion restricts them from going against the natural physiology of conception (contextual factors). Hence, it is worth considering that the capability approach holds the potential to direct key stakeholders to invest wisely, set realistic goals for improving population health and execute feasible, realistic, accessible, culturally sensitive and practical programmes to improve the well-being and quality of life of the targeted population.

\section{Relevance of the capability approach to the Sustainable Developmental Goals}

In view of the current challenges that our world is encountering, there is no doubt that while it is essential to have goals that are realistic, time bound, understandable, measurable and achievable, it is equally imperative to design interventions suited to the capability and function of the targeted population. Considering the notion presented by the capability approach, it can be reflected that a possible reason for the difficulties in achievement of the Millennium Developmental Goals was that human capabilities were neither well thought out when targeting interventions nor considered when measuring the poverty, inequality and well-being of the population.
The key aim of the proposed post2015 Sustainable Developmental Goals is to transform the world by alleviating poverty, protecting the planet, fostering healthy environments, augmenting prosperity, enhancing peace and growing partnerships $(10,11)$. The interdisciplinary nature of the capability approach not only enhances the relevance of this framework to the Sustainable Developmental Goals but also provides a unique perspective for analysing a wide range of populationbased issues such as ill-health, disabilities, poverty, hunger, inequality, gender disparities and conflicts. Moreover, this framework has the potential to provide an innovative theoretical lens to the health care professionals, health economists, researchers, policy-makers, and other key stakeholders to collectively strive towards achieving the Sustainable Development Goals in all parts of the world.

Although 17 Sustainable Developmental Goals with their 169 targets were intended to address disparities surrounding population health, the same sets of interventions cannot be applied to achieve these targets in high-income, middle-income and low-income countries. Considering the capability approach, it is worth noting that the population of each region/country has diverse sets of capabilities, functions, resources, cultural contexts, socioeconomic situations and geopolitical characteristics. Hence, before planning and executing interventions to achieve the Sustainable Developmental Goals at diverse geographic locations, it seems essential to assess the human capabilities, functions, agency, resources and contextual factors of the targeted population. This initial assessment of the population's beings and doings through the lens of the capability approach will be useful in planning, executing, monitoring and evaluating efforts to achieve the goal of population health. Consequently, this well-thought-out approach will enhance the population's freedom (capabilities and functions), access to resources and ability to make positive choices to achieve well-being, prosperity and peace that stand out as the foremost targets of the Sustainable Developmental Goals.

To conclude, this reflective paper discusses the capability approach as an analytic framework that provides an innovative perspective for analysing wellbeing, progress and development of an individual from the standpoint of a person's beings and doings (capabilities and functioning), freedom, resources and other contextual factors in a person's internal and external environment. Despite the existing differences in the developmental indicators of countries across the world, the theoretical lens of the capability approach has the potential to enhance health worldwide and assist the interdisciplinary team of stakeholders to achieve the Sustainable Developmental Goals uniformly in different parts of the world.

\section{Acknowledgement}

We are thankful to Dr Kimberly Jarvis for reviewing the paper.

\section{Funding: None.}

Competing interests: None declared

\section{References}

1. Sen A. Human rights and capabilities.J Hum Dev. 2005;6(2):15166.

2. Sen A. Commodities and capabilities. New Delhi: Oxford University Press; 1999.

3. Alkire S. Why the capability approach? J Hum Dev. 2005;6(1):115-35.
4. Chiappero-Martinetti E, Venkatapuram S. The capability approach: a framework for population studies. Etude Popul Afr. 2014;28(2):708-20.

5. Cookson R. QALYs and the capability approach. Health Econ. 2005;14(8):817-30. PMID: 15693028 
6. Robeyns I. The capability approach: a theoretical survey. J Hum Dev. 2005;6(1):93-117.

7. Law I, Widdows $\mathrm{H}$. Conceptualising health: insights from the capability approach. Health Care Anal. 2008;16(4):303-14. PMID: 17922192

8. Hall PA, Taylor RCR, Barnes L. A capabilities approach to population health and public policy-making. Rev Epidemiol Sante Publique. 2013;61:S177-83. PMID: 23835148

9. Vizard P, Fukuda-Parr S, Elson D. Introduction: the capability approach and human rights. J Human Dev Capabil. 2011;12(1):1-22.
10. Robert KW, Parris TM, Leiserowitz AA. What is sustainable development? Goals, indicators, values, and practice. Environment: Science and Policy for Sustainable Development. 2005;47(3):8-21.

11. United Nations. Transforming our world: the 2030 Agenda for Sustainable Development (https://sustainabledevelopment. un.org/post2015/transformingourworld, accessed 16 November 2015). 